\title{
Cardiovascular System Findings Method
}

National Cancer Institute

\section{Source}

National Cancer Institute. Cardiovascular System Findings Method. NCI Thesaurus. Code C123979.

The technique used to administer the cardiovascular system assessment. 